\title{
Pollen germination as affected by pollen age
}

\section{in cherimoya}

\author{
P. Rosell *, V. Galán Saúco *, M. Herrero ** \\ * I.C.I.A. Dep, Fruticultura Tropical, Apartado 60, 38200 La Laguna, Tenerife, Spain \\ *** Estación Experimental de Aula Dei (CSIC) Dep, Pomología, Ap. 202, 50080 Zaragoza, Spain
}

\begin{abstract}
Cherimoya (Annona cherimola (Mill.)) is a subtropical fruit tree, which is cultivated in a good range of subtropical regions. In most of these areas the crop relies on hand pollination. However, following this practice, erratic fruit set is often produced, which could be related to problems in pollen handling. Indeed, very little is known of the time that the pollen remains viable and on which is the best stage to collect the anthers or pollen from the flower. The aim of this work is to evaluate pollen germinability prior and after anther dehiscence and also how the age of pollen affects pollen vigor, understood as speed of germination. Pollen samples at different times following anther dehiscence were germinated in vitro and in vivo. Pollen up to 90 min following dehiscence performed as well as freshly dehisced pollen. However, the pollen taken 120 min following dehiscence, showed a clear reduction in vigor and germinated much slower in vivo. To overcome this short pollen germinability, pollen was taken from anthers 30 and $5 \mathrm{~h}$ prior to natural anther dehiscence and compared with pollen taken at anther dehiscence and $20 \mathrm{~h}$ later. However, a reduction in germination rate was obtained in pollen taken prior to anther dehiscence. The narrow stage at which pollen can be collected together to its ephemeral germinability explains erratic results obtained following hand pollination in this crop and these results provide the clues for an adequate pollen handling.
\end{abstract}

Keywords: Annona cherimola; Pollen germination; Pollen vigor; Pollination; Pollen tetrad 


\section{Introduction}

Cherimoya (Annona cherimola (Mill.)) is a subtropical fruit tree cultivated either at low altitude in the subtropics or in tropicals areas at altitude higher than $1000 \mathrm{~m}$ above sea level. The good organoleptic quality and market of this crop has lead to its dissemination through other regions outside its area of origin. In most of these areas, while there is a good vegetative adaptation, the trees fail to produce regular crops. The main reason for these low yields is a failure in pollination, which can be solved by hand pollination, a common cultural practice in countries as Chile (Schwarzenberg, 1946), Spain (Guirado Sánchez et al., 2001), India (Thakur and Sing, 1965a) or New Zealand (Richardson and Anderson, 1990). However, following hand pollination often erratic results are produced.

The floral cycle of this species was early described (Wester, 1910), the flowers are hermaphrodite with a strategy of dichogamy protogyny to favor cross pollination. At anthesis, the flower is female and has a receptive pistil. This stage lasts 1-2 days and then, generally in the first hours of the evening, the stigma starts to lose receptivity, the flower becomes male and the anthers initiate dehiscence (Rosell and Galán, 1995 and Guirado Sánchez et al., 2001). However, this strategy to favor outcrossing is often impaired in agricultural conditions due to the lack of pollinator agents. Pollination problems have been also related to immaturity of the pollen at the time of shedding, since pollen was observed to be dispersed and initiating germination at the stage of tetrads (Thakur and Sing, 1965a, Thakur and Sing, 1965b and Saavedra, 1977). In addition, pollen quality appears to be a limiting factor that often impairs successful pollination, and hence an adequate crop in this species. This is in part related to the little knowledge that is available on the factors that affect pollen germinability in cherimoya. While external factors as temperature clearly play a role (Rosell et al., 1999), little is known on how internal factors, as pollen age affect pollen performance.

This paper studies (1) how pollen age affects pollen vigor, expressed as speed of germination (Shivanna and Cresti, 1989 and Shivanna et al., 1991) and (2) pollen germinability prior or after anther dehiscence. While this information can be of interest in any species, in cherimoya it has also clear implications in the subsequent pollen handling process.

\section{Materials and methods}


Seventeen years old 'Fino de Jete' cherimoya plants were used. The work was carried out during the maximum flowering period (July-August). Pollen was collected from 5-10 flowers, in the same stage, in each of 10 plants randomly chosen. Anthers were collected from flowers in different development stages prior to anthesis: at $30 \mathrm{~h}(\mathrm{D}-30 \mathrm{~h})$ and $5 \mathrm{~h}(\mathrm{D}-5 \mathrm{~h})$ before dehiscence (Guirado Sánchez et al., 2001), at anther dehiscence (D), and also at time intervals following anther dehiscence: $60 \mathrm{~min}$ (D + $60 \mathrm{~min}), 90 \mathrm{~min}(\mathrm{D}+90 \mathrm{~min}), 120 \mathrm{~min}(\mathrm{D}+120 \mathrm{~min})$ and $20 \mathrm{~h}(\mathrm{D}+20 \mathrm{~h})$. Anthers collected prior to dehiscence were forced to dehisce by placing then 3 min under the sun. The pollen $\mathrm{D}+20 \mathrm{~h}$ type was stored for $20 \mathrm{~h}$ in Petri dishes at $7-8^{\circ} \mathrm{C}$ (Guirado Sánchez et al., 2001) and the other pollen types were left at room temperature until germination. For both in vivo and in vitro pollen germination the stamens were left with the pollen, since previous work indicated this as a requisite for proper germination (Rosell et al., 1999).

For in vitro pollen germination the pollen grains were cultured in drops of BKS medium (Rosell et al., 1999). The cultures were scored for germination after 10, 30, $60 \mathrm{~min}$ and $20 \mathrm{~h}$. Over 100 pollen grains per sample were scored and between 4 and 10 replicates were recorded for each pollen type and time of germination.

For in vivo pollen germination the flowers to be pollinated were bagged 1 day prior to anthesis and then pollinated on the day of anthesis with the help of a camel-hair. The pollinated stigmas were collected at defined times after pollination. In each flower, half the stigmatic cone was shaved with the help of a scalpel and the collected stigmas mounted on a slide with a staining-fixing solution (Rosell et al., 1999). Over 300 pollen grains per sample were scored and between 13 and 17 flowers were examined for each time and pollen type. Data, from the in vitro and in vivo experiments, were subject to an analysis of variance and means were compared by using Tukey's test.

\section{Results}

\section{Age effect on pollen germination and vigor}

Pollen germination was evaluated in vitro and in vivo with pollen taken at different times after anther dehiscence. In vitro pollen germination increased along the first hour following sowing in the media, attaining germination values close to those obtained after $20 \mathrm{~h}$ of sowing (Fig. 1). The pollen taken up to $90 \mathrm{~min}$ following dehiscence $(\mathrm{D}+90 \mathrm{~min}$ ) performed as well as freshly dehisced pollen (D). 
However, the pollen taken 120 min after dehiscence $(D+120 \mathrm{~min})$ showed a significant reduction in germination. Thus, while the final germination $(20 \mathrm{~h}$ ) of freshly dehisced pollen averages $60 \%$, the pollen taken 120 min after dehiscence gave a final germination of $17 \%$. This experiment was repeated with pollen coming from a different area and these results were confirmed showing a reduction in the germination of pollen taken at 120 min after dehiscence (35\%) as compared with freshly dehisced pollen $(70 \%)$.

To evaluate if this reduction in germination capability was also recorded in vivo, pollen taken at dehiscence (D), 60 (D + $60 \mathrm{~min})$ and $120 \mathrm{~min}(\mathrm{D}+120 \mathrm{~min})$ after dehiscence was used to pollinate detached flowers kept in moist florist foam. In the observations, made $2 \mathrm{~h}$ after pollination (Fig. 2), the percentage of germination of pollen type $(\mathrm{D}+120 \mathrm{~min}), 18 \%$, was significantly different from that obtained with the pollen types (D) and (D+60 min), both $32 \%$. These results agree with those obtained in in vitro tests along the first hour of germination. However, after $20 \mathrm{~h}$ in the stigma, the pollen type (D+120 min) behaved much better than in vitro (Fig. 1) and germination percentage was not significantly different from freshly dehisced pollen (D) and pollen (D + 60 min) (Fig. 2).

\section{Germination of pollen coming from different anther developmental stages}

To evaluate if this short pollen germination capability can be overcome using pollen prior to anther dehiscence, pollen taken $30 \mathrm{~h}(\mathrm{D}-30 \mathrm{~h})$ and $5 \mathrm{~h}(\mathrm{D}-5 \mathrm{~h})$ prior to anther dehiscence was compared with pollen at anther dehiscence (D) and $20 \mathrm{~h}$ later $(\mathrm{D}+20 \mathrm{~h})$ and this pollen was used to pollinate flowers at anthesis in the tree. The stigmas were scored for pollen germination and for presence of tetrads (Fig. 3). Pollen showed the highest germination (53\%) at anther dehiscence (D) (Fig. 3) and the

percentage of germination was lower before anther dehiscence, $33 \%$ at D $-5 \mathrm{~h}$ and $14 \%$ at D - $30 \mathrm{~h}$. The germination value was also low at $\mathrm{D}+20 \mathrm{~h}(5 \%)$.

Both, individual grains and grains grouped in tetrads were observed in pollinated stigmas. The proportion of pollen grains grouped in tetrads is inversely related with germination values (Fig. 3). Thus, when maximum germination (53\%) takes place, the percentage of grains grouped in tetrads is $16 \%$, and when germination reaches the minimum values (14\% and $5 \%)$ the number of pollen grains that remain in tetrads is elevated ( $45 \%$ and $57 \%$, respectively). This occurred independently of the developmental stage of the anther. 


\section{Discussion}

Pollen of cherimoya has showed to have an ephemeral life and to loose vigor rapidly following anther dehiscence. In fact, $120 \mathrm{~min}$ after being shed from the anthers pollen had a reduced vigor and germination rate in vitro and a reduction of vigor in vivo. This could be related to the fact that pollen is shed in a tricellular stage (Rosell et al., 1999) and tricellular pollen has been shown, in other species, to have a shorter viability than bicellular pollen (Brewbaker, 1957 and Heslop-Harrison, 1987).

The loss of vigor shown by the cherimoya pollen can be compared with previous observations in other plant species under stress conditions (Shivanna and Cresti, 1989 and Shivanna et al., 1991), which indicated that these conditions produced a vigor reduction prior to a loss of germination capacity. The different response obtained in vitro and in vivo for pollen $(\mathrm{D}+120 \mathrm{~min})$, after $20 \mathrm{~h}$ of germination, can be explained considering that the changes in the membranes structure of the vegetative cell, due to partial dehydration after dehiscence, are recovered later upon hydration at the stigma (Shivanna and Heslop-Harrison, 1981 and Heslop-Harrison, 1987) but this did not occur in the artificial media.

To overcome the difficulties of manipulating the cherimoya pollen with such a short life, the possibility to collect pollen prior to anther dehiscence has been explored. The evaluation of the in vivo germination capacity of pollen shows, as expected, that the maximum value of germination was obtained with pollen at the time of natural anther dehiscence. The low value obtained when the pollen was extracted forcing the anthers $30 \mathrm{~h}$ before natural dehiscence, suggests that the last few hours within the anther are important for complete pollen development.

The relationship between poor germination and number of pollen grains grouped in tetrads is in line with previous observations and it has been questioned that this may reflect an inmature stage of the pollen upon anther dehiscence (Thakur and Sing, 1965a and Thakur and Sing, 1965b and Saavedra, 1977). However, cherimoya pollen as other Annona species, is dispersed in tetrads, which are considered the functional unit (Le Thomas et al., 1986 and Tsou and Fu, 2002). Previous work in this species (Rosell et al., 1999) showed that the pollen tube emission takes place by the proximal pole, and the separation of pollen grains inside the tetrads is a consequence of the emerging pollen tubes, as it has also been observed in other Annonaceae (Le Thomas et al., 1986). Thus, the amount of pollen grains that separate upon germination, as well as the number of pollen grains remaining in tetrads, are a consequence of the greater or smaller degree of pollen germination and not the opposite. 
These results convert to the point that cherimoya pollen has a short life following anther dehiscence and also that pollen can be collected from the anthers in a short window of time. Given the ephemeral life of the cherimoya flower, which in the climatic conditions of this study does not reach $48 \mathrm{~h}$ of lifespan, with a maximum period of stigmatic receptivity of $30 \mathrm{~h}$, it can be inferred that the pollination process to be effective also must take place in a short window of time. This fragile pollen germinability explains erratic results often obtained following hand pollination and all together these results contribute to a better understanding of the pollen collection and subsequent handling of the pollination procedure.

\section{Acknowledgements}

Financial support for this work came from project grants CICYT AGL2003-05318-C02-01, and INIA RTA02-97.

\section{References}

Brewbaker, 1957 J.L. Brewbaker, Pollen cytology and self-incompatibility systems in plants, J. Hered. 48 (1957), pp. 271-277.

Guirado Sánchez et al., 2001 Guirado Sánchez, E., J.M. Hermoso González, M.A. Pérez de Oteyza, J. García-Tapia Bello y J.M. Farré Massip, 2001. Polinización del Chirimoyo. Consejería de Agricultura y Pesca. Junta de Andalucía Sevilla (España), p. 52.

Heslop-Harrison, 1987 J. Heslop-Harrison, Pollen germination and pollen-tube growth, Int. Rev. Cytol. 107 (1987), pp. 1-78

Le Thomas et al., 1986 A. Le Thomas, W. Morawetz and M. Waha, Pollen of palaeo-and neotropical Annonaceae: definition of the aperture by morphological and functional characters. In: S. Blackmore and I.K. Ferguson, Editors, Pollen and spores. Form and function. Linnean Soc. Symp. Ser. vol. 12, Academic Press, London (1986), pp. 375-388.

Richardson and Anderson, 1990 A.C. Richardson and P.A. Anderson, Is hand pollination of cherimoya necessary?, Orchard. N. Z. (1990), pp. 21-25. 
Rosell and Galán, 1995 P. Rosell and V. Galán, Notes on rhythms observed in the duration of flower anthesis throughout flowering in cherimoya on the island of Tenerife, Fruits 50 (1995) (3), pp. 233237.

Rosell et al., 1999 P. Rosell, M. Herrero and V. Galán Saúco, Pollen germination of cherimoya (Annona cherimola (Mill.)). In vivo characterization and optimization of in vitro germination, Sci. Hort. 81 (1999), pp. 251-265.

Saavedra, 1977 E. Saavedra, Influence of pollen grain stage at the time of hand pollination as a factor on fruit set of Cherimoya, HortScience 12 (1977) (2), pp. 117-118.

Schwarzenberg, 1946 C. Schwarzenberg, Polinización artificial del chirimoyo, Agr. Téc. Chile 6 (1946) (2), pp. 156-172.

Shivanna and Heslop-Harrison, 1981 K.R. Shivanna and J. Heslop-Harrison, Membrane state and pollen viability, Ann. Bot. 47 (1981), pp. 759-770.

Shivanna and Cresti, 1989 K.R. Shivanna and M. Cresti, Effects of high humidity and temperature stress on pollen membrane integrity and pollen vigor in Nicotiana tabacum, Sex Plant Reprod. 2 (1989), pp. 137-141. View Record in Scopus | Cited By in Scopus (5)

Shivanna et al., 1991 K.R. Shivanna, H.F. Linkens and M. Cresti, Pollen viability and pollen vigor, Theor. Appl. Genet. 81 (1991) (1), pp. 38-42.

Thakur and Sing, 1965a D.R. Thakur and R.N. Sing, Studies on pollen morphology, pollination and fruit set in some annonas, Indian J. Hort. 22 (1965), pp. 10-18.

Thakur and Sing, 1965b D.R. Thakur and R.N. Sing, Studies on floral biology of Annonas, Indian J. Hort. 22 (1965), pp. 238-253.

Tsou and Fu, 2002 C.-H. Tsou and Y.-L. Fu, Tetrad pollen formation in Annona (Annonaceae): Proexine formation and binding mechanism, Am. J. Bot. 89 (2002) (5), pp. 734-747

Wester, 1910 P.J. Wester, Pollination experiments with Anonas, Bull. Torrey Bot. Cl. 37 (1910), pp. $529-539$. 


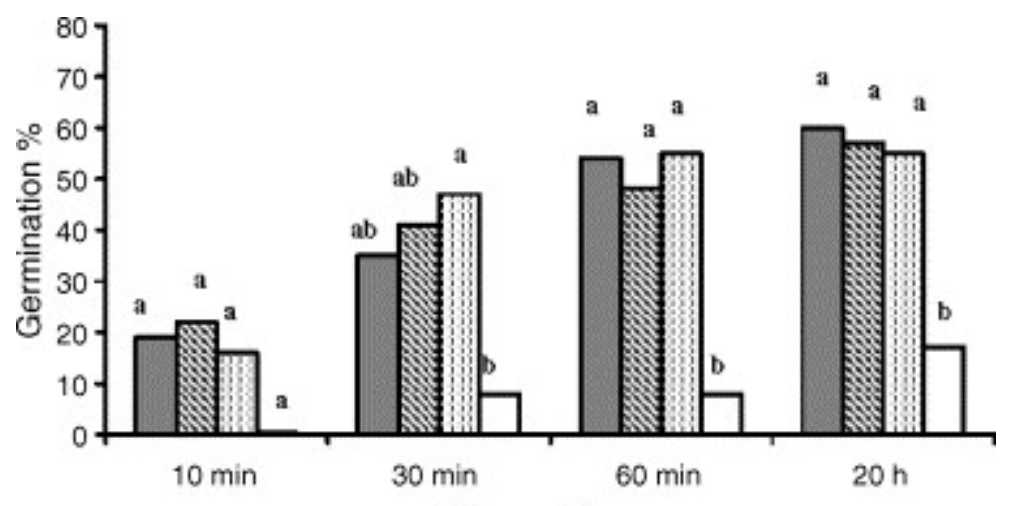

Observations

口D $\mathbf{\nabla D}+60 \mathrm{~m} \quad \mathbf{D D}+90 \mathrm{~m} \quad \mathbf{D}+120 \mathrm{~m}$

Treatment means followed by the same letters are not significantly different at $P \leq 0.05$ (Tukey test)

Fig. 1. In vitro pollen germination of pollen sown at anther dehiscence (D) and at different times intervals following anther dehiscence: $60 \mathrm{~min}(\mathrm{D}+60 \mathrm{~min}), 90 \mathrm{~min}(\mathrm{D}+90 \mathrm{~min})$ and $120 \mathrm{~min}$ $(\mathrm{D}+120 \mathrm{~min})$ and observed at different times after sowing.

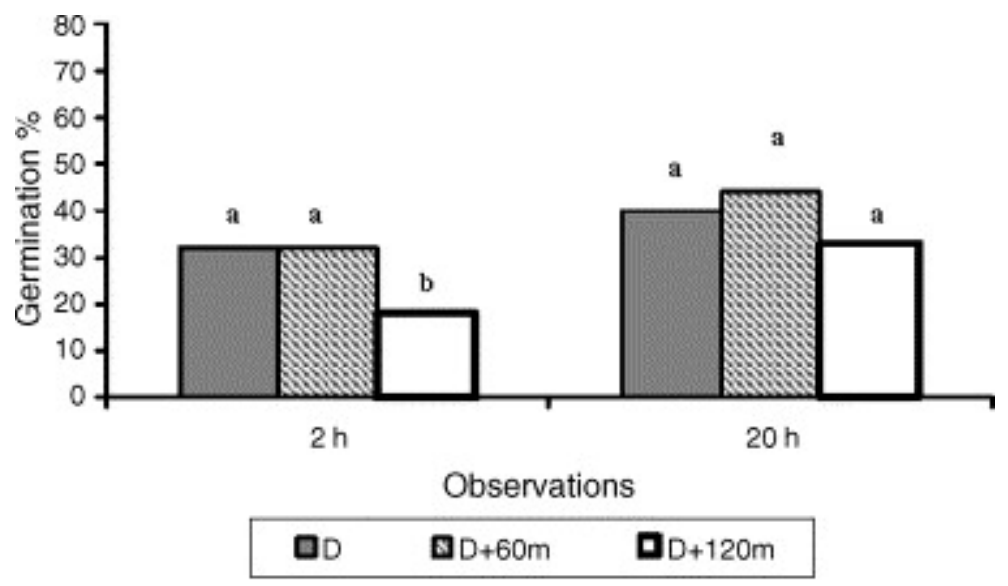

Treatment means followed by the same lefters are not significantly different at $P \leq 0.05$ (Tukey test)

Fig. 2. In vivo pollen germination of pollen at anther dehiscence (D), $60 \mathrm{~min}(\mathrm{D}+60 \mathrm{~min})$ and $120 \mathrm{~min}(\mathrm{D}+120 \mathrm{~min})$ after dehiscence. Data recorded 2 and $20 \mathrm{~h}$ after stigmas pollination. 


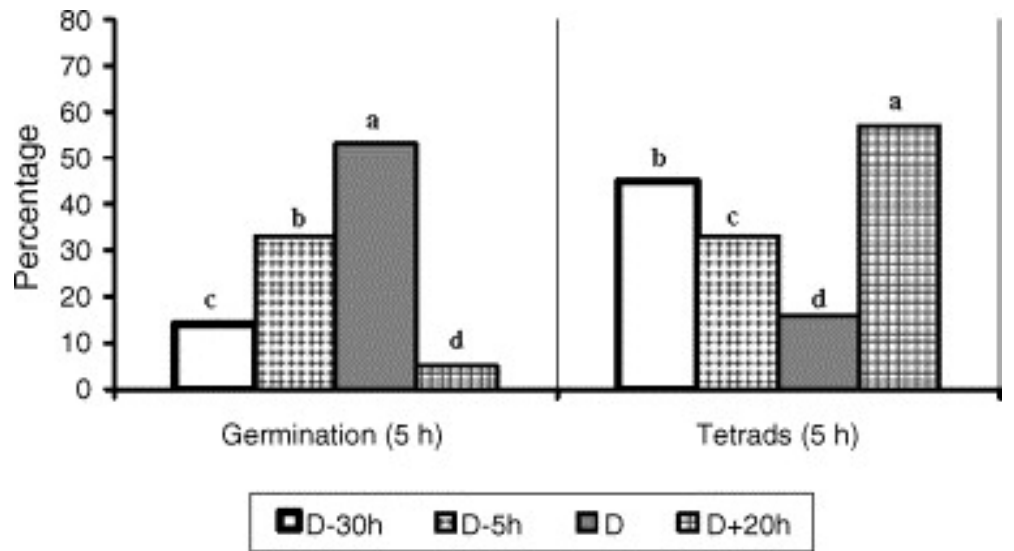

Treatment means followed by the same letters are not significantly different at $P \leq 0.05$ (Tukey test)

Fig. 3. In vivo pollen germination and presence of tetrads, following pollinations with pollen coming from anthers at different stages of development: anther dehiscence (D), $30 \mathrm{~h}(\mathrm{D}-30 \mathrm{~h})$ and $5 \mathrm{~h}$ $(\mathrm{D}-5 \mathrm{~h})$ prior to anther dehiscence, and $20 \mathrm{~h}$ after dehiscence $(\mathrm{D}+20 \mathrm{~h})$. Data recorded $5 \mathrm{~h}$ after stigmas pollination. 